\title{
El Estado del Desarrollo Local en América Latina: obstáculos, facilitadores y liderazgos
}

\author{
Fernando Pintos*
}

\section{Introducción}

Desde una perspectiva de desarrollo territorial, la actuación en las sociedades locales supone reflexionar críticamente sobre las acciones llevadas a cabo para producirlas como tales. Las sociedades locales son producciones fajinosas que implican un cierto tipo de socialidad, determinadas formas de agencia y un sistema de representaciones. Lo local constituye uma realidad fenomenológica compleja, entramado de relaciones de inmediatez, construcciones simbólicas y sentimientos de pertenencia a través de los cuales se construye la identidad (y la diferencia) de una comunidad. En fin, lo local es una construcción para sí antes que uma cualidad en sí.

Pensar lo local como una producción es el supuesto de cualquier intervención que se base en la comprensión y en la introducción de cambios en las prácticas sociales. Es suponerlo como realidad estructurante de la acción y estructurada a partir de ella.

Estas definiciones teóricas y estratégicas tienen consecuencias metodológicas, y suponen ciertos postulados epistemológicos de base no siempre discutidos pero que merecen explicitarse.

Investigar y actuar al mismo tiempo es un desafío, pues supone un continuo flujo de intervenciones en el mundo, no siempre articulables: las del actor con intereses pragmáticos y la del observador con intereses cognoscitivos. Estos roles están dominados por lógicas bien diferentes y deben suponer una ruptura a partir de que los intereses de la acción en ambos casos son diferentes.

Esta presentación expone una serie de conclusiones sobre las diferentes dimensiones de los procesos de desarrollo local, (en adelante, DL) a partir de la reflexión sobre las propias experiencias en las que CLAEH ha participado como impulsor en los últimos veinte años, como agente y como observador atento de sus propias prácticas.

En particular, algunas de las mismas están vinculadas a la investigación sobre obstáculos y facilitadores del DL llevado a cabo con otras organizaciones de América Latina en trece países de nuestro subcontinente, en el marco del "Ciclo de fortalecimiento de las capacidades de ALOP-NOVIB para intervenir en Desarrollo Local en América Latina"1.

La experiencia en procesos de DL nos permite acumular evidencia empírica en el sentido de que aquéllos que han tenido un grado importante de consolidación han alcanzado a articular la multidimensionalidad (política, cultural, económica, social) como eje de la actuación, la incorporación de sus contenidos a las políticas públicas y, por lo general, la estrecha conexión con otros procesos territoriales en marcha.

La puesta en marcha y el funcionamiento de los procesos de DL está por tanto asociada a las conexiones existentes en los diferentes territorios entre instituciones políticas, sociedad local, empresas y cultura comunitaria.

a. Un factor reiteradamente encontrado como disparador de iniciativas de DL fueron los câmbios de $\operatorname{los}^{\prime} 90$, que sentaron condiciones para una fuerte heterogeneización de la sociedad civil, expresión de una fuerte fragmentación social.

En algunos casos este factor ha operado como impulsor de la pluralidad de iniciativas, pero paradójicamente, ha terminado siendo su propio limitante, pues ha dificultado llegar a arreglos que satisfagan a la variedad de intereses y de actores. Al tiempo que ha erosionado la posibilidad de generar comunicación, cuando los universos simbólicos y las referencias identitarias tienden a volverse fragmentarias y fuertemente autorreferidas.

\footnotetext{
* Centro Latinoamericano de Economía Humana (CLAEH). E-mail: fpintos@claeh.org.uy
} 
b. En la generación de articulación, la construcción de liderazgos territoriales es otro de los factores identificados como fundamentales. En nuestras actuales sociedades sometidas a la emergencia de continuas alteraciones de sus patrones de normalidad, ello implica desprenderse de viejos modos de comportamiento y de pensamiento. El gran desafío para los líderes locales actuales es alcanzar niveles de consenso para unir acuerdo territorial y cambio social. Cómo hacer de sociedades fragmentadas, proyectos colectivos que no eternicen empates que benefician a los que siempre ganan cuando ellos se producen, aparece como unos de los principales desafíos de los líderes locales.

El nivel local el liderazgo no se concentra necesariamente en el sistema estatal y, específicamente, no se confunde con el poder municipal. El liderazgo vinculado a procesos de transformación no es una función exclusiva de las autoridades públicas, sino que puede generarse en otros sistemas sociales, y a veces es deseable para el éxito de los procesos que ello suceda.

Ser líder depende de la decisión de asumir la función de ponerse al frente, tener visión de futuro, comunicar y construir confianza, tanto o más que de la posición que se ocupe formalmente. Pero es un rol al que los gobiernos municipales no deben renunciar, siempre y cuando estén dispuestos a compartirlo y a consolidar modalidades de cooperación persistentes.

El liderazgo para impulsar procesos de desarrollo local exige:

- Tener una visión hacia dónde se va;

- Incluir los intereses de una multiplicidad de actores en el corto y el largo plazo;

- Buscar equilibrios que compensen los conflictos inevitables y hasta deseables;

- Sopesar a la hora de tomar decisiones las expectativas y los objetivos con las consecuencias no buscadas o no deseadas que el proceso pueda tener.

Estas competencias asociadas al liderazgo no se vinculan solamente con capacidades gerenciales y de management, sino que plantean desafíos que hacen a la posibilidad de la gobernanza local; son políticos, implican producir y gestionar poder.

c. En tercer lugar, podemos señalar como variable asociada al DL, el rol que los gobiernos locales y nacionales desempeñan. No necesariamente la legitimidad democrática es la que les otorga a los mismos credenciales para liderar procesos de desarrollo local, pues no es condición suficiente para que los mismos se generen. El sistema político no es naturalmente el "locus" del cambio y de la generación de proyectos territoriales. Sí es cierto, que en cada experiência sustentable de desarrollo local en $\mathrm{AL}$, en algún momento se da la deliberación sobre el poder y el Estado y la interpelación a sus actores constituyentes. En función de ello, la inclusión de los mismos a los procesos de desarrollo local es imprescindible para asegurar la multidimensionalidad e integralidad referida.

En algún punto los procesos de desarrollo local demandan la generación de cierta institucionalidad que le asegure la permanencia en el tiempo. Pero la institucionalidad debe ser parte del proceso y no un a priori del mismo. Cuando la misma contribuye a procesos exitosos de DL, facilita la implementación de proyectos de gestión asociada, pero estos últimos son el indicador de gobernanza local y no la normatividad per se.

La gestión asociada de planes-proyectos es un componente que le da contenido a la participación en el nivel local. Sin embargo la misma tiende a generar en los niveles políticos desconfianza hacia liderazgos comunitarios, que son interpretados como desafíos a su legitimidad democrática. Cuando tal desafío tiene lugar, en realidad no es esta legitimidad la cuestionada por los actores sociales, sino ciertos mecanismos tradicionales de legitimación, como el clientelismo.

Los procesos de desarrollo local que han alcanzado niveles de sostenibilidad han logrado generar confianza entre los diversos tipos de liderazgos, mediante el establecimiento de mecanismos de negociación que especifican y reasignan roles entre los diferentes actores.

d. Finalmente, ha sido una constante en las experiencias analizadas el vínculo entre dinâmica económica y nuevas formas de producción con cambios en las estructuras de socialización y en los valores compartidos. 
Algunos emprendimientos económicos que logran trascender la cultura reactiva de los localismos han podido sostenerse divorciados del territorio. El desafío de los procesos de DL en el plano económico es reapropiarse de emprendimientos exitosos que, por los imperativos de la lógica empresarial, el manejo de los tiempos o la incompatibilidad de los modos de actuación con los predominantes en el territorio, han preferido externalizarse antes que acordar con el sistema local'.

A continuación presentaré lo que, a partir de la reflexión teórica y práctica generada por la participación en procesos de desarrollo local, entiendo como los principales obstáculos y facilitadores de los mismos. Más adelante, expondré una tipología de liderazgos y los analizaré en función de sus capacidades y limitaciones para remover esos bloqueos y potenciar los factores que coadyuvan a expandir los procesos referidos.

\section{Facilitadores y obstaculizadores del desarrollo local}

Hemos clasificado a los factores que operan en favoreciendo o desestimulando los procesos de DL en siete tipos: cognitivos, organizacionales, relacionales, culturales, normativos, económicofinancieros y de infraestructura. A partir de esta tipología, hemos identificado en el conjunto de casos factores que operan como obstáculos o como facilitadotes de esos procesos. A continuación expondremos las principales conclusiones a las que arribamos en ese sentido.

\subsection{Los factores que favorecen los procesos}

\subsubsection{Cognitivos}

O sea, los saberes necesarios para intervenir y generar vectores de cambio en el territorio. En primer lugar, el conjunto de los saberes pragmáticos de los propios actores que, si bien tienen las implicancias propias del "nativo" (que ve el territorio desde el ángulo particular del agente interesado) puede aportar elementos claves para el desenvolvimiento de los procesos de DL. Por su parte, los conocimientos técnicos aportan algo diferente que el sistema local no posee, como el pensar globalmente y la capacidad de planificación, así como potencial movilizador. Pero pueden llegar a debilitar el tejido local si se presentan como sustitutos de los saberes endógenos. Cuando la centralidad de los saberes exógenos al territorio está sobredimensionada, éstos pueden devenir en contraproducentes para movilizar a los actores locales

\subsubsection{Organizacionales}

Es decir, las formas establecidas de participación y acción colectiva. La existencia de antecedentes organizativos en un territorio (para otros tipos de iniciativas incluso, no necesariamente de DL) operan como facilitadores de emprendimientos locales. A veces esos antecedentes operan retrasando procesos si los vínculos entre actores son de tipo clientelar, pero por lo general son preferibles territorios con experiencias de articulación entre actores que sin ellas.

Los actores independientes (endógenos o exógenos) pueden aportar su poca sospechabilidad de estar "contaminados" políticamente para facilitar el encuentro de propósitos comunes y su materialización en proyectos viables. Estos actores, o el Estado en sus diversos niveles, cuando predomina en él una intención legítima, pueden reunir iniciativas sueltas y potenciarlas al vincularlas entre sí. Los procesos de DL pueden iniciarse o potenciarse si se identifica una necesidad sentida que no logra articularse como demanda organizada en el espacio público, y se la toma como punto de apoyo para impulsarlos. Ejemplo de ello son las iniciativas de incorporar nuevas perspectivas - como la de género -, o sectores sociales (cómo los jóvenes) que corrientemente tienen niveles bajos de participación en espacios colectivos, para que operen como innovadores en espacios de participación local agotados 
(como pueden llegar a ser los presupuestos participativos).

\subsubsection{Relacionales}

Con ello queremos decir las formas de vínculo entre los diferentes actores, particularmente las relaciones de poder. Los facilitadores más destacados a este nivel están asociados a las formas de vincularse el Estado central o los municipios con sus ciudadanos y con sus formas organizativas. La existencia de voluntad política de impulsar experiencias permanentes de incidencia social en la política pública juega un rol preponderante en el impulso al DL. La planificación participativa con visión regional le da a esas experiencias una perspectiva global, que suele aportar el actor político de gobierno (superando las meras reivindicaciones sectoriales o localistas.) Ese aporte puede hacerlo en la medida que se piense a sí mismo como líder, lo que implica cumplir un rol algo más complejo que el de articulador solamente.

\subsubsection{Culturales}

O sea, la solidez de las prácticas sociales, devenidas en significados compartidos. En particular las prácticas democráticas en un país constituyen un fuerte pilar para sostener experiencias de descentralización, participación y desarrollo económico (empresarios populares, intercambio de experiencias, aprovechamiento de iniciativas sueltas, voluntad política).El manejo de las decisiones y de las voluntades en forma arbitraria, instaurado como pauta socialmente legitimada, opera como un serio obstáculo a cualquier experiencia participacionista. Por ello las políticas nacionales de fortalecimiento democrático constituyen un fuerte aliado de los procesos locales.

\subsubsection{Normativos}

Ello significa, los marcos jurídicos o reglamentos de funcionamiento aceptados, que operan como delimitador de las reglas de juego establecidas. Procesos de descentralización en marcha, institucionalización de espacios de concertación local, normativas que obliguen a los gobiernos a consultar a sus sociedades, pueden verse como facilitadores de DL. Sin embargo, no operan como tales por el mero hecho de su existencia. Para que sean factores realmente operativos, los actores deben verlos más como marco y como resultado de los procesos, que como una meta de los mismos. De lo contrario, tienden a convertirse en estructuras vacías o en domesticadores de la participación ciudadana. Por ello es positivo que existan iniciativas que no transcurran por los ámbitos oficiales y que no intenten cruzarse con ellos. Rehuir a la institucionalización puede constituir una estrategia eficiente para fortalecer incluso a la misma institucionalidad establecida.

\subsubsection{Económicos y financieros}

El conjunto de recursos y de riqueza generada activados en procesos de DL. La cercanía a fuentes estables de financiamiento, a mercados regionales sustentables y capacidad financiera de los agentes interventores para sostener los proyectos, facilitan aunque no garantizan el êxito en los procesos de DL. Más que dinero, lo que los mismos precisan son posibilidades de generar producción colocable extra localmente. Cuando fallan, o no existen canales de comercialización de los emprendimientos locales, devienen los bloqueos que debilitan todo el esfuerzo por generar estructuras organizativas multiactorales. La integración de los emprendimientos económicos a conglomerados que tienen como referencia la región o el país aportan mercados y know how inexistente localmente.

\subsubsection{Infraestructura}

INTERAÇÕES, Campo Grande, v. 9, n. 2, p. 217-228, jul./dez. 2008. 
Vale decir, las instalaciones y vías de comunicación y transporte que potencien el capital territorial. Sin caminos, puentes, vías y medios de comunicación el desarrollo local no puede salir de una "fase primitiva", lindante con el "folklorismo". Las políticas estatales nacionales y provinciales (o estaduales) pueden ser facilitadores en la medida que enganchen com necesidades territoriales. De la misma manera, más a escala local, las obras en los municípios son condición necesaria para la mejora de la calidad de vida de sectores excluidos del acceso a servicios básicos, pero el "obrismo" no constituye de por sí desarrollo local. Asociar desarrollo a "más cosas en un territorio" es confundirlo con acumulación de riqueza. Pero la acumulación de riqueza se transforma en palanca de desarrollo si deviene en capital territorial, puesto en marcha junto a procesos participativos para generar política pública, excedente económico y fortalecimiento del capital social.

\subsection{Los factores que dificultan el desarrollo local}

\subsubsection{Organizativos}

Uno de los obstáculos principales al DL es la debilidad institucional de los Estados, particularmente a nivel municipal. Ello se expresa a tres niveles:

- A nivel macro, los Estado Centrales carecen normalmente de estrategias nacionales coherentes de desarrollo local. O si existen, están teñidas de sectorialismo y son materias intra-ministeriales.

- A nivel meso, cuando las políticas diseñadas centralmente se transfieren a los territorios a sus unidades ejecutivas, la débil conexión de las mismas con el tejido local hace poco fecundas las iniciativas de DL.

- A nivel micro, sea derivado de políticas municipales, provinciales o nacionales, la instrumentación de estrategias de desarrollo local tiene serias dificultades de producir sinergias entre los actores por las carencias de recursos humanos y de know how local.

Las debilidades organizativas se extienden por todo el tejido local y no quedan concentradas en el Estado. El desprendimiento de funciones estatales y su transferencia en los ' 90 a la sociedad civil no tuvo contrapartida en la generación de capacidades para hacer sostenibles proyectos a largo plazo y procesos sociales duraderos. Hecho éste potenciado por el actuar descoordinado de muchas organizaciones exógenas que "aterrizan" en una comarca, intervienen en sus procesos mientras tienen financiamiento y se retiran irresponsablemente cuando se les acaba. El desarrollo local así queda dejado a la sumatoria de proyectos, cuya articulación queda librada a la obra de una entidad metafísica o de una mano invisible.

\subsubsection{Cognitivos}

Con relación a los conocimientos pragmáticos puestos en práctica por los distintos actores en el territorio, existen obstáculos de diferente naturaleza. Por un lado, la brecha educativa existente en nuestras sociedades dificulta la adquisición de herramientas mínimas para conocer, interpretar y proyectar las acciones más allá de la cotidianeidad por parte de muchos sectores sociales. Sin esa base, el trabajo de capacitación se vuelve aún más difícil, porque faltan ciertas habilidades cognitivas mínimas. En cuanto a saberes más sociales, constituye un obstáculo importante la debilidad de conocimientos frecuentemente percibida en las comunidades locales para el ejercicio de la cooperación. Prima el cortoplacismo, el individualismo y la rentabilidad inmediata de las acciones. Finalmente, ya en un nivel más pragmático, sea entre los actores sociales como los de gobierno, las capacitaciones para gestionar procesos de desarrollo, no suelen tener continuidad y están dominadas por la lógica del management, que se centra en lo administrativo más que en las competencias de tipo social. Es posible encontrar expertice en la formulación de políticas, pero en la etapa de implementación los resultados son disímiles, pues la gestión del conflicto, la negociación, no son los fuertes de la misma. Este aspecto se relaciona con las características de la formación 
universitaria en nuestros países, fuertemente academicista y a veces prejuiciosa respecto a formar en competencias sociales.

\subsubsection{Relacionales}

Buena parte de las debilidades de los procesos de desarrollo local están asociadas a las consecuencias de la fragmentación social, el desempleo, la exclusión. Estos fenômenos impactan fortaleciendo el auto interés, la inmediatez de las demandas, el cortoplacismo, de actores sociales y políticos (que se ven urgidos de dar respuestas inmediatas a sus ciudadanos). En un contexto histórico-cultural de clientelismo y patrimonialismo, uno de los resultados de estos procesos es el reforzamiento de la dependencia del Estado, de las elites políticas o de los agentes sociales que ofician de intermediadores ante el municipio, el gobierno provincial o el Estado central. Aunque desde los ámbitos municipales o locales haya un esfuerzo por generar espacios de encuentro con la sociedad civil, la desconfianza hacia el sistema político que prevalece en América Latina impacta en el sentido opuesto.

Por otro lado, la institucionalización en esferas estatales de espacios de participación es un arma de doble filo: al tiempo que facilita su estabilización más allá de los avatares políticos, le pone un corsé a la participación y la hace discurrir dentro de la lógica del sistema político. Existe un tipo particular de conflicto de "baja intensidad "que algunas veces sube a la superficie, pero que dificulta que los municipios puedan devenir en líderes territoriales: la baja predisposición al cambio de las burocracias y de las tecnocracias, que suelen poner trabas a todo proceso que amenace su estabilidad. Corporativismo mediante, esta actitud encuentra en los sindicatos la forma organizativa bajo la cual presentar sus intereses particulares como legítimos.

Otra fuente de conflictos que puede ser identificada obstáculo para el desarrollo local, es el tipo de relacionamiento entre los actores políticos centrado en el boicot de las iniciativas del adversario. Ello hace casi imposible las políticas a largo plazo, pues cualquier propuesta de articulación multiactoral desde el gobierno local es sospechada de espureidad y atacada por la oposición.

En cuanto a los obstáculos generados en el relacionamiento entre los actores económicos y entre ellos y otros actores locales, se detectan trabas relacionadas con la viabilidad de los proyectos de desarrollo económico y con la dependencia creciente de conglomerados trasnacionales a territoriales cuyos referentes de negociación trascienden al propio estado nación.

\subsubsection{Jurídicos}

En relación con las competencias y atribuciones de los estados y municipios la normativa per se no resuelve las carencias en los otros planos referidos anteriormente. Incluso algunas legislaciones nacionales, diciendo impulsar procesos de descentralización, han homogeneizado a los territorios por medio de una legislación que les impone plataformas parejas para gestionar la relación entre Estado y sociedad civil. También debe destacarse como obstáculo el anacronismo de muchas normas jurídicas reguladoras de las organizaciones de la sociedad civil y de la vida económica, que no se ajustan a los cambios en las formas de asociatividad producto de los procesos de globalización y de la propia desregulación de las relaciones entre los agentes económicos.

\subsubsection{Culturales}

A las prácticas prebendarias y al clientelismo, así como al centralismo como componente de hábitos de nuestras sociedades, debemos agregar el personalismo y el verticalismo con que los dirigentes locales, sean sociales o políticos, tienden a gestionar su liderazgo. La contra cara de ello es la falta de autonomía de las formas colectivas comunitarias y la escasa renovación de las elites locales, (sean elites empresariales, partidarias o barriales), que bloquean 
la emergencia de agentes dinámicos (mujeres, jóvenes, etc.).

Los particularismos y el vivir al día también se suman a este mapeo de obstáculos culturales que configuran modos de actuación contrarios a una visión integral y territorial del desarrollo. Así, éste se percibe como resultado natural de intervenciones parciales; antes que proceso es una sumatoria de momentos.

\subsubsection{Problemas de financiamiento}

La fuerte dependencia de los gobiernos municipales con relación a las instancias de gobierno nacional, provincial o estadual impacta negativamente con mayor fuerza cuando, existe una fuerte contradicción entre las atribuciones que establecen las distintas normativas y los recursos financieros con que cuentan efectivamente los gobiernos municipales. Ejemplo de ello, es la Ley del Fondo de Desarrollo Económico y Social de El Salvador, que transfiere el $7 \%$ del presupuesto nacional para los Gobiernos Municipales, cuando éstos tienen que cumplir con 28 atribuciones que se les asignan. Allí es necesaria una redistribución de competencias entre ámbitos nacionales y locales en el marco de un proceso de descentralización del Estado, incluído su sistema tributario y fiscal, que esté guiada por la solidaridad territorial.

En relación con el sistema económico, los obstáculos se concentran en la carencia de inversiones, la competencia de la economía ilegal, la disparidad en el acceso a servicios, las condiciones actuales de las tendencias de la macroeconomía y la dificultad para integrar a conglomerados territoriales a emprendedores que están en el sector.

\subsubsection{Déficit de Infraestructura}

La debilidad de las políticas nacionales de desarrollo local impacta negativamente en la forma en que se definen a nivel de los Estados centrales las inversiones en infraestructura. En tanto esas inversiones trascienden las capacidades de los municipios urge construir una nueva lógica de relacionamiento local-nacional, que articule papeles diferentes a instancias locales y centrales de gobierno. Para reformular el papel local, se debe repensar al Estado central, ambos al mismo tiempo.

Pero las carencias de infraestructura no se reducen a las obras de tipo vial, de riego o canalización, o vinculadas a la economía regional. También son obstáculos al desarrollo las dificultades en el acceso a las tecnologías y al software necesario para una mejora de la gestión. En general, existe la tendencia, tanto en el ámbito de gobierno como de sociedad civil, a identificar los recursos para la realización de obras de infraestructura con un uso improvisado de los mismos y a la escasa planificación por parte de los equipos técnicos y políticos de los municipios.

\section{Los actores de los procesos de desarrollo local}

Como fue mencionado en el capítulo anterior hay que diferenciar participación de liderazgo. Los actores de los procesos de Desarrollo Local tienen grados variados de compromiso con los mismos. Ser agente de desarrollo pone al actor en capacidad para innovar e impulsar cambios en sus respectivas esferas de actuación. Como también fue señalado, liderar procesos implica articular iniciativas de los agentes locales con una visión integral y sistémica de los mismos.

Para comprender los factores que inciden en la generación de liderazgos debemos elaboramos una tipología de líderes de procesos locales en que existe una apelación territorial. La utilización de esta expresión permite:

- identificar en una gama variada de experiencias las formas en que esa referencia es expresada discursivamente, aunque sus trasfondos semánticos seguramente no sean coincidentes.

- no forzar a priori una diferenciación doctrinaria entre procesos "falsos "y "verdaderos" 
de DL, construida por un iluminado agente externo, sino recoger las representaciones que los actores se hacen de sus prácticas, para identificar obstáculos y facilitadores de la integralidad mencionada anteriormente.

En un ida y vuelta entre análisis empírico y elaboración conceptual hemos generados estos tipos ideales de liderazgos con "referencia territorial" que apelan en sus discursos a paradigmas de actuación referidos por ellos como relacionados al desarrollo local.

a. Los estrategas de la planeación

Estos actores suelen presentarse en el territorio desde la plataforma de las "planificaciones estratégicas", pudiendo ser actores políticos, consultores, académicos. Logran reunir voluntades en procesos que presentan al territorio como el referente de actuación y califican a la planeación como el punto de arranque del desarrollo local. Según sea su naturaleza, su intervención suele estar marcada por los ciclos electorales, académicos o de la financiación externa. Son potentes en generar movilización en el corto plazo y débiles en la traducción de la misma en cambios efectivos en las condiciones de vida de la población.

b. Los portadores de políticas contra la pobreza

En buena medida reactiva a los primeros, pretenden generar impactos rápidos en mejoramiento de la calidad de vida de la población local, o de al menos algunos sectores. Logran reunir voluntades para impulsar acciones, pero el territorio resulta un mero receptáculo de decisiones tomadas en espacios a-territoriales. Pueden ser agentes estatales que siempre han sospechado de los liderazgos locales, o fundaciones nacionales o internacionales. El rasgo común es el asistencialismo de sus prácticas y el desconocimiento del territorio. Tienen como potencialidad el acceso a fuentes de financiamiento nacional e internacional, por la urgencia de atacar situaciones de pobreza y marginalidad derivadas de las políticas económicas de los ‘90, y como debilidad una visión centralista que constituye la principal amenaza a la sostenibilidad de los efectos de sus intervenciones.

c. Los líderes participacionistas

Son los convocadores por excelencia a la movilización de actores locales. Pueden hacerlo desde plataformas diferentes (el municipio, las ONG's, los partidos políticos, las fundaciones internacionales o las agencias de cooperación) y a través de apelaciones de la más variada naturaleza (el presupuesto participativo, el poder local, la autoayuda, el voluntariado o el cooperativismo). Su capacidad de reunir actores tras una meta inmediata puede ser su principal fortaleza, pero tienen serias dificultades para sostener los procesos y generar proyectos a largo plazo. Oscilan entre la apelación a la resistencia política, el sectorialismo cooperativo, la desconfianza de los actores de gobierno y el mutuo socorro.

\section{d. Los potenciadores de cadenas de valor}

Por lo general, son agentes económicos con iniciativa y empuje para liderar procesos novedosos. Suelen aportar lo que los anteriores no están en condiciones de generar, pero sus iniciativas tienden a ser sectoriales, pues encuentran sus interlocutores entre actores económicos parecidos a ellos. Su principal debilidad es congeniar lógicas con actores con otros tiempos y otros intereses.

\section{e. Los aportantes de infraestructura}

Gobiernos municipales, agencias estatales centrales, donantes extranjeros que entienden que la primera (y casi única) dimensión del desarrollo de un territorio es la generación de infraestructura, sea ésta de servicios o productiva. En este caso se espera que por derrame el territorio produzca bienestar entre sus habitantes. No necesariamente se oponen a la participación social, pero ven en el "tipo c" un liderazgo competidor, pues se lo representa como generador de demandas que pueden atender directamente, sin intermediarios. Aportan una visión pragmática muchas veces, pero no se proyectan más allá de ese nivel.

\section{f. Los articuladores}

Son los formados en las diferentes versiones del DL, que redefinen el vínculo con las sociedades locales a partir de sus aprendizajes académicos. Integran gobiernos locales, ONG's, 
oficinas de los gobiernos centrales o instituciones educativas. Si tienen alguna capacidad de decisión y están legitimados socialmente, logran generar espacios multiactorales, pero su escaso poder político y económico hace que sus iniciativas se debiliten rápidamente. Se relacionan bien con el tipo " $\mathrm{a}$ " y con el " $\mathrm{c}$ ", pero van perdiendo credibilidad en la medida que su liderazgo no se traduce en "hechos concretos". A veces mezclan sus roles de profesional y de político, pues deben responder a dos lógicas de actuación que tienen como destinatarios actores diferentes.

Estos tipos deben entenderse como categorías puras; frecuentemente en los actores concretos puede convivir la lógica de más de uno de ellos. Como tipos ideales tienen algún punto de contacto con la realidad empírica, pero no se identifican plenamente con ella; por tanto su utilidad es analítica. Cada uno representa una forma de relacionarse con el territorio que no son mutuamente excluyentes y que un agente de desarrollo local debería tener presente si pretende convocar a otros y liderar procesos sostenibles en el tiempo: la planificación, la participación, las políticas sociales de impacto inmediato, la generación de infraestructura, el reforzamiento de los niveles de relacionamiento y de confianza entre actores locales y la generación de riqueza.

Si cruzamos esta tipología con una distinción de los mismos en base a su rol en la estructura social desde sus potencialidades y limitaciones para liderar procesos de desarrollo local nos encontraríamos con el siguiente paisaje.

Estas son hipotéticas combinaciones de tipos de liderazgo y de actor, con impactos bien distintos en el territorio. No agotan todas las posibilidades pero puede servir para ordenar el mapa de factores y actores que inciden positivamente o negativamente en los procesos de DL en América Latina.

\begin{tabular}{|c|c|c|c|c|c|c|c|c|}
\hline \multicolumn{9}{|c|}{ TIPO DE ACTOR } \\
\hline & \multicolumn{2}{|c|}{ POLÍTICO DE GOBIERNO } & \multicolumn{2}{|c|}{ SOCIOTERRITORIAL } & \multicolumn{2}{|c|}{ EXOGENO } & \multicolumn{2}{|c|}{ ECONOMICO } \\
\hline & potencialidades & limitaciones & potencialidades & limitaciones & potencialidades & limitaciones & potencialidades & limitaciones \\
\hline Tipo a & $\begin{array}{l}\text { la legitimidad que } \\
\text { le otorga el voto } \\
\text { democrático y } \\
\text { popular para } \\
\text { impulsar la } \\
\text { planificación }\end{array}$ & $\begin{array}{l}\text { La } \\
\text { perentoriedad } \\
\text { de los tiempos } \\
\text { políticos }\end{array}$ & $\begin{array}{l}\text { Conocimiento del } \\
\text { territorio desde la } \\
\text { perspectiva de } \\
\text { actor }\end{array}$ & $\begin{array}{l}\text { Debilidad } \\
\text { capital social } \\
\text { para ejecutar } \\
\text { planificaciones }\end{array}$ & $\begin{array}{l}\text { Conocimiento } \\
\text { técnicos para } \\
\text { trascender el aquí y } \\
\text { ahoralocales }\end{array}$ & $\begin{array}{l}\text { Desconocimiento } \\
\text { del territorio (o } \\
\text { "aplicando la rabí } \\
\text { olerá" planes } \\
\text { idénticos con algún } \\
\text { "aire local") }\end{array}$ & $\begin{array}{l}\text { Iniciativa propia } \\
\text { del ámbito } \\
\text { empresarial }\end{array}$ & $\begin{array}{l}\text { Dificultad para } \\
\text { "esperar" a los } \\
\text { otros }\end{array}$ \\
\hline Tipo b & $\begin{array}{l}\text { La ejecutividad } \\
\text { para } \\
\text { instrumentarla }\end{array}$ & $\begin{array}{l}\text { El centralismo } \\
\text { en el diseño e } \\
\text { implementación }\end{array}$ & $\begin{array}{l}\text { Cercanía a las } \\
\text { necesidades }\end{array}$ & $\begin{array}{l}\text { Dificultades } \\
\text { para superar el } \\
\text { nivel de } \\
\text { autoayuda }\end{array}$ & $\begin{array}{l}\text { Posibilidad de } \\
\text { trascender los } \\
\text { conflictos locales } \\
\text { para identificar } \\
\text { grupos objetivo }\end{array}$ & $\begin{array}{l}\text { Asistencialismo y } \\
\text { generación de } \\
\text { dependência }\end{array}$ & $\begin{array}{l}\text { Concepción de la } \\
\text { responsabilidad } \\
\text { empresarial }\end{array}$ & $\begin{array}{l}\text { Dificultad para ser } \\
\text { más que "donador } \\
\text { de cosas a los } \\
\text { pobres" }\end{array}$ \\
\hline Tipo c & $\begin{array}{l}\text { La capacidad } \\
\text { negociadora }\end{array}$ & $\begin{array}{l}\text { La dificultad } \\
\text { para canalizar } \\
\text { demandas y } \\
\text { conflictos de } \\
\text { larga data }\end{array}$ & $\begin{array}{l}\text { Facilidad para } \\
\text { comunicar con los } \\
\text { iguales }\end{array}$ & $\begin{array}{l}\text { Tendencia al } \\
\text { basismo }\end{array}$ & $\begin{array}{l}\text { Capacidad de } \\
\text { intermediación } \\
\text { entre intereses }\end{array}$ & $\begin{array}{l}\text { Los tiempos } \\
\text { acotados de su } \\
\text { intervención }\end{array}$ & $\begin{array}{l}\text { Logística y know } \\
\text { how para ovilizar }\end{array}$ & $\begin{array}{l}\text { Incorporación de } \\
\text { los otros como } \\
\text { receptores de } \\
\text { iniciativas }\end{array}$ \\
\hline Tipo d & $\begin{array}{l}\text { El acceso a } \\
\text { recursos, } \\
\text { contactos e } \\
\text { información }\end{array}$ & $\begin{array}{l}\text { La tendencia a } \\
\text { la sectorialidad }\end{array}$ & $\begin{array}{l}\text { Cercanía de los } \\
\text { mercados }\end{array}$ & $\begin{array}{l}\text { Dificultad para } \\
\text { trascender } \\
\text { fuera de los } \\
\text { mercados } \\
\text { locales }\end{array}$ & $\begin{array}{l}\text { Acceso a recursos } \\
\text { e información }\end{array}$ & $\begin{array}{l}\text { Sectorialidad de la } \\
\text { intervención }\end{array}$ & $\begin{array}{l}\text { Acceso a } \\
\text { mercados } \\
\text { externos, know } \\
\text { how }\end{array}$ & $\begin{array}{l}\text { "desconexión del } \\
\text { territorio" }\end{array}$ \\
\hline Tipo e & $\begin{array}{l}\text { El acceso a } \\
\text { recursos y la } \\
\text { cercanía a las } \\
\text { demandas }\end{array}$ & $\begin{array}{l}\text { El "cordón } \\
\text { cunetismo" que } \\
\text { busca el redito } \\
\text { político } \\
\text { inmediato }\end{array}$ & $\begin{array}{l}\text { Facilidad para } \\
\text { canalizar } \\
\text { demandas locales }\end{array}$ & $\begin{array}{l}\text { Imposibilidad } \\
\text { de trascender } \\
\text { la } \\
\text { reivindicación } \\
\text { barrial }\end{array}$ & $\begin{array}{l}\text { Acceso a recursos } \\
\text { externos al territorio }\end{array}$ & $\begin{array}{l}\text { Des } \\
\text { responsabilización } \\
\text { pos intervención } \\
\text { por los impactos no } \\
\text { buscados }\end{array}$ & $\begin{array}{l}\text { Ejecutividad y } \\
\text { recursos }\end{array}$ & Imagen de donador \\
\hline Tipo $f$ & $\begin{array}{l}\text { Legitimidad para } \\
\text { convocar }\end{array}$ & $\begin{array}{l}\text { Pocos recursos } \\
\text { humanos y } \\
\text { materiales para } \\
\text { traducir los } \\
\text { consensos en } \\
\text { hechos }\end{array}$ & $\begin{array}{l}\text { Cercanía a los } \\
\text { actores locales }\end{array}$ & $\begin{array}{l}\text { Sospechabilida } \\
\text { d de intereses } \\
\text { particularistas }\end{array}$ & $\begin{array}{l}\text { Know how } \\
\text { localmente escaso }\end{array}$ & $\begin{array}{l}\text { Dificultades para } \\
\text { generar estructuras } \\
\text { exógeno } \\
\text { independientes }\end{array}$ & $\begin{array}{l}\text { Iniciativa y } \\
\text { responsabilidad } \\
\text { empresarial }\end{array}$ & $\begin{array}{l}\text { Avasallamiento de } \\
\text { los tiempos de los } \\
\text { otros actores }\end{array}$ \\
\hline
\end{tabular}

Si cruzamos los estilos de liderazgo con sus respectivas capacidades para facilitar procesos de desarrollo local o para obstruirlos con sus prácticas y nos concentramos en los extremos (allí donde impactan más positivamente o más negativamente a la sostenibilidad de los mismos) nos encontraremos con este panorama: 


\begin{tabular}{|l|l|l|l|l|l|l|l|l|l|l|l|l|l|l|l|}
\hline \multicolumn{1}{|c|}{ Tipo de líderes } & \multicolumn{5}{c|}{ Obstáculos } & \multicolumn{7}{c|}{ Facilitadores } \\
\hline & Org. & Cog. & Rel. & Jur. & Inf. & Ecofin. & Cul. & Org. & Cog. & Rel. & Jur. & Inf. & Ecofin. & Cul. \\
\hline A estrategas de la planeación & & & & & & & & & & & & & & \\
\hline B portadores de pol.pobreza & & & & & & & & & & & & & & \\
\hline C líderes participacionistas & & & & & & & & & & & & & & \\
\hline D potenciadores de cadenas valor & & & & & & & & & & & & & & \\
\hline E aportantes de infraestructura & & & & & & & & & & & & & & \\
\hline F articuladores & & & & & & & & & & & & & & \\
\hline
\end{tabular}

- El tipo a) es bueno para aportar conocimientos extraterritoriales necesarios para el DL, pero su accionar tiene casi nulo impacto al nivel de la generación de infraestructura, al límite de ser visualizado como un obstaculizador de su concreción;

- El tipo b) facilita el desenvolvimiento de iniciativas de impacto inmediato por los recursos que suele volcar al territorio, pero debilita el tejido local con sus prácticas centralistas;

- El tipo c) es un buen articulador pero se transforma en un obstáculo muchas veces a la hora de atraer recursos económicos por su tendencia deliberacionista;

- El tipo d) favorece el desarrollo local por su capacidad de agregar valor a la economía territorial, pero puede afectar negativamente la confianza interactoral por la dificultad de armonizar sus tiempos y sus intereses con otros de naturaleza social o cultural;

- El tipo e) como su nombre lo indica, es un facilitador de recursos para infraestructura, pero sus prácticas son un gran obstáculo para el cambio cultural;

- El tipo f) es un buen generador de sinergias a corto plazo, pero sus débiles capacidades para concretar iniciativas los llevan muchas veces a debilitar organizativamente a los actores locales, al imponerles institucionalidades no necesarias o al ver éstos frustradas sus expectativas.

\section{Conclusiones: algunas pocas pistas para fortalecer los procesos de desarrollo local}

La experiencia en procesos de desarrollo local en los que CLAEH ha participado con mayor o menos grado de compromiso, y la investigación referida inicialmente nos permiten hablar de algunas líneas de intervención desde las que se puede impactar significativamente: descentralización, educación, fortalecimiento del capital social y participación.

a. descentralización

Sea por la falta de expertice de los gobiernos locales, por la ausencia de políticas nacionales al respecto o por las debilidades de procesos desarrollados en los últimos años, la descentralización sigue siendo tema de primer orden de la agenda latinoamericana. El centralismo culturalmente arraigado, junto a las prácticas patrimonialistas, hace que las iniciativas desconcentradoras de poder terminen en generación de institucionalidad normativa que no logra superar ni los obstáculos financieros, ni la carencia de capacidades de gestión al nivel de los gobiernos locales.

Cuando pensamos en qué actores deberíamos fortalecer para potenciar la descentralización, se hace necesario operar en tres direcciones: los gobiernos locales (tanto en sus capacidades de gestión como en la fortaleza de sus instituciones); los estados centrales, sin el concurso de los cuales no pueden diseñarse estrategias nacionales de desarrollo local; y la sociedad civil, cuyas organizaciones se caracterizan por la renuencia a la integración en estrategias planificadas de actuación a nivel local y por la baja capacidad de incidencia sobre las políticas públicas.

En relación con este último tipo de actor, las estrategias de fortalecimiento de los procesos de DL deben apuntar a generar cambios actitudinales (reconocimiento del propio espacio, valor y poder de cambio); procedimentales (apropiación de pasos concretos y eficaces de actuación para incidir en el cambio deseado) y de conocimientos (conceptos y relaciones de causalidad, 
entre teoría y práctica, y teorías que posibilitan interpretar la realidad y construir los sentidos).

La forma de relacionamiento entre estos tres tipos de actores en el plano local y nacional marca el tipo de descentralización en el cual estemos pensando: una que pone particular énfasis a la apropiación por las sociedades locales de competencias para auto producirse y de recursos para hacerlo posible y otra más vinculada a la construcción de poder adentro y entre los niveles estatales que enfatiza la transferencia de recursos y potestades a instancias subnacionales. Son dos formas no contradictorias de pensar la descentralización, pero sí diferentes. En cualquier de ellas deben incluirse, de alguna manera la diversidad de actores presentes en el territorio, incluyendo gobiernos locales y sociedad civil.

Ello significa sostener formas de participación ciudadana e incidencia en las políticas públicas, como medio para la inclusión social. Las mismas parecen ser condiciones necesarias para articular la descentralización con proyectos territoriales y sistemas sociales. Incluso la participación ciudadana puede operar de despertador del actor político de gobierno, tradicionalmente ensimismado, auto referente y poco proclive a compartir poder.

b. educación

Con este significante en realidad se engloban una multiplicidad de significados que podrían encontrar su rasgo común en la expresión de "formación para la vida". El fortalecimiento de los sistemas educativos, formales y no formales, no es una cuestión asociada a la tradicional demanda de mayores recursos financieros para extender los servicios. Cuando se piensa en DL, se está pensando en expandir la educación en número de personas, en tiempo vital y en transformarla, para que su lógica de reproducción auto referida e iluminista deje lugar a expresiones mucho más vinculadas a las necesidades de los territorios, que potencien las capacidades de acción de las colectividades locales en el desarrollo social, económico y cultural a través de la formación para la vida y del desenvolvimiento de novedosas formas de participación social.

Los actores a potenciar acá son múltiples, pero más que "capacitarlos" de los que se trata es de generar agentes de desarrollo local en todos aquellos ámbitos donde existan procesos de generación y reformulación de aprendizajes, sea en el ámbito formal como en el no formal. Además urge transformar a los sistemas educativos institucionalizados en sistemas abiertos que perciban que en el desarrollo del territorio se juega su propia existencia, y que sean productores de conocimiento y no solo reproductores de saberes generados por otros y apropiados tardíamente.

c. capital social

Las estrategias de fortalecimiento de la educación, de las sinergias entre actores sociales y económicos y de la descentralización política se potencian si producen mejoras sustantivas en las habilidades sociales para "actuar juntos". El asociativismo local es uno de los componentes necesarios, aunque no suficiente, para generar gobernanza local. Por ello cada uno de los três temas anteriores debe ser pensado en relación con el otro, para que la participación no devenga en demandas de ciudadanos atomizados, sino en ciudadanía, en acción colectiva.

Es relevante rescatar para ello la idea de la ciudadanía como un espacio de disputa de sentido. Ello significa que su representación como proceso de descubrimiento y construcción de derechos, compite con visiones del mismo en tanto acceso al consumo, como ejercicio de facultades jurídicas o de desarrollo de las potencialidades individuales. Sin embargo, cuando pensamos la ciudadanía desde la perspectiva de la acción colectiva, su desarrollo demanda hoy de visiones integrales que asocien la con la educación, la organización, la identificación de necesidades y las reformas institucionales.

El fortalecimiento de la ciudadanía está asociado por ende a la generación de institucionalidad (en el sentido de nuevas formas de ser, actuar y pensar), al diálogo intercultural, a la construcción de sujetos colectivos, al estímulo a espacios de encuentro, a la potenciación de los vínculos entre lo local y lo nacional y a la reintroducción de lo político.

d. desarrollo económico local: 
Bajo este rótulo incorporamos una serie de preocupaciones recurrentes en expertos y agentes de desarrollo local, que plantean la necesidad de dar sustento a la participación, fortaleciendo la capacidad del sistema local de generar excedente económico.

En ese sentido, una de las líneas de trabajo de mayor impacto es el fortalecimiento de las capacidades existentes de las experiencias de producción en pequeña escala (mypes, cooperativas) que tienen serias dificultades para ampliar su mercado, como en incorporar a los empresarios y a las inversiones de origen exógeno a la lógica del desarrollo territorial. En parte derivado de la fortaleza y de la autosuficiencia de estos agentes para auto producirse al margen de las preocupaciones de los actores locales; y en otra medida, de la reticencia de los primeros a incorporar la lógica empresarial al sistema social.

Estas líneas de intervención tienen fuerte capacidad para enganchar procesos y de alguna medida todas las demás variables quedan asociadas a factores a ellas asociados: construcción de poder, acción colectiva organizada, cambio cultural y generación de riqueza, componentes centrales de cualquier proceso social integral. Desde estos cuatro "temas de conversación" tenemos plataformas amplias para potenciar nuestros impactos como agentes de desarrollo local y por ende de cambio social, en los próximos años.

\section{Notas}

${ }^{1}$ Este ciclo se realizó entre marzo de 2005 y febrero de 2006 y uno de sus componentes fue un mapeo de limitaciones y potencialidades del desarrollo local en 13 países latinoamericanos, para el cual Se llevaron a cabo más de 60 entrevistas a expertos y actores del desarrollo local. El trabajo fue coordinado por CLAEH, com participación de organizaciones que integran la Asociación Latinoamericana de Organizaciones de Promoción (ALOP) y contó con financiación de la Agencia Holandesa de Cooperación (NOVIB).

${ }^{2}$ Las iniciativas de cambio económico pueden ser impulsoras de procesos de DL, en la medida en que su aspecto más desintegrador sea neutralizado. Los complejos sistemas sociales actuales se caracterizan por contener la paradoja como rasgo constituyente. Así, el proceso de globalización (con todas sus facetas) que a primera vista, genera tendencias homogeneizadoras, también da lugar a reacciones de tipo inverso y a nuevos procesos en que la dimensión local y el rescate de la especificidad cultural ocupan un lugar central.
}

\section{Referencias}

APPADURAI, Arjun. La modernidad desbordada. Dimensiones culturales de la globalización. Montevideo: TrilceFCE, 2001.

AROCENA, José. El Desarrollo Local: un desafío contemporáneo. Montevideo: CLAEH-Nueva Sociedad, 1995.

BECK, Ulrich: ¿Qué es la globalización?. Barcelona: Paidós, 2000.

BERVEJILLO, Federico. La reinvención del territorio. En Desarrollo Local en la Globalización. Montevideo: CLAEH, 1999.

ENRÍQUEZ, Alberto y GALLICHIO, Enrique. Gobernanza y desarrollo local. Documento pre-sentado en la Escuela de Verano MOST-UNESCO. Organizada por el Centro Latinoa-mericano de Economía Humana (CLAEH) en Punta del Este (Uruguay). Octubre, 2003. Disponible en: <http://www.claeh.org.uy/archivos/ Documento_MOST_Gobernanza_Enriquez_Gallicchio.pdf>.

FINOT, Iván: Descentralización en América Latina: teoría y práctica. Santiago de Chile. Serie Gestión Pública de la Comisión Económica para América Latina y el Caribe (CEPAL) - Instituto Latinoamericano y del Caribe de Planificación Económica y Social (ILPES). Mayo, 2001. Disponible en: < http://www.eclac.cl/publicaciones/Ilpes/ 1/LCL1521P/lc11521e.pdf>.

GALLICCHIO, Enrique. El desarrollo local, sus retos y desafíos. Sistematización de experiencias de desarrollo local en Chile y Uruguay. In: CONFERENCIA INTERNACIONALSOBRE “DESCENTRALIZACIÓN, DESARROLLO ECONÓMICO LOCAL V PARTICIPACIÓN”, 17 al 20 de junio de 2002, Arequipa. Anais... Perú, 2002.

GARCÍA CANCLINI, Néstor. Globalizarnos o defender la identidad. ¿Cómo salir de esta opción?. Revista Nueva Sociedad, n.163, Caracas, Septiembre-octubre, 2000.

GALLICCHIO, Enrique y CAMEJO, Alejandra. Desarrollo local y descentralización en América Latina. Montevideo: CLAEH - DIBA, 2005.

MASSOLO, Alejandra. Participación de las mujeres en los gobiernos locales de América Latina. Instituto Nacional de las Mujeres. México, 2003. Disponible en: <http://www.rimisp.org/boletines/bol52/doc3.zip>.

QUINTERO LÓPEZ, Rafael. El asociativismo municipal en América Latina. Federación Latinoamericana de Ciudades, Municipalidades y Asociaciones (FLACMA) (2005). http://www.rimisp.org/boletines/bol52/doc1.zip>. 